\title{
PREOCUPACIONES TERRENAS EN UNA COFRADÍA. LAS ÁNIMAS BENDITAS DEL PURGATORIO DE JUJUY EN EL PERÍODO COLONIAL
}

\author{
POR \\ ENRIQUE NORMANDO CRUZ \\ CONICET - Argentina
}

\section{RESUMEN}

En este artículo se analiza la cofradía de las Ánimas Benditas del Purgatorio de Jujuy (sur del Charcas), teniendo en cuenta los testamentos e inventarios de bienes del siglo XVIII. En los que se observó que las preocupaciones principales fueron la adquisición y aumento de bienes y recursos, la elección de autoridades, y la participación en el mercantilismo local.

PALABRAS CLAVE: cofradía, Jujuy, animas, colonial

\section{CONCERNS ABOUT LAND IN A BROTHERHOOD. THE HOLY SOULS OF THE PURGATORY OF JUJUY IN THE COLONIAL PERIOD}

\begin{abstract}
This article analyses the brotherhood of the Holy Souls of the Purgatory of Jujuy (south of Charcas), taking into account the testaments and inventories of goods in the XVIII ${ }^{\text {th }}$ century, in which it was observed that the main concerns were the acquisition and increase of goods and resources, the election of authorities, and the participation in local mercantilism.
\end{abstract}

KEY WORDS: brotherhood, Jujuy, souls, colonial

Recibido/Received 13-07-2010

Aceptado/Accepted 31-03-2012 
Las cofradías religiosas son asociaciones cristianas con fines sociales relacionados a la vida y muerte. En este artículo se analiza la cofradía de las Ánimas Benditas del Purgatorio de Jujuy, teniendo en cuenta una serie elaborada de testamentos e inventarios de bienes en una centuria. El objetivo no fue encontrar y describir la cofradía, sino que su existencia quedó en evidencia en los registros de donaciones, limosnas y cuerpo de autoridades, que la fuente documental permitió apreciar.

En esta asociación se consagraron devotamente a preocupaciones después de la muerte, ${ }^{1}$ y especialmente, los cofrades se preocuparon por los asuntos terrenos, como la adquisición, fomento y aumento de los bienes y recursos, elección de autoridades, y participación en el financiamiento del capitalismo mercantil local. ${ }^{2}$

En el artículo, primero se consideran los estudios sobre las cofradías religiosas en la Argentina, y se describen a las que existen en el espacio de estudio (especialmente a las cofradías religiosas que tienen similares características sociales a las de Jujuy, un distrito de composición mayoritaria indígena en el medio de valles y sierras rurales andinos). Luego se analiza de manera precisa, las mandas forzosas que dan origen a esta y otras cofradías, y finalmente, se presentan los fondos económicos constituidos por los bienes y recursos que recibe y recolecta, las autoridades que la gobiernan, la reglamentación que la rige, el rol que le cupo en la financiación del mercantilismo local, y la atención social característica de la devoción por las Ánimas Benditas del Purgatorio.

\section{LAS COFRADÍAS RELIGIOSAS DE JUJUY}

Las cofradías religiosas son asociaciones del Antiguo Régimen Hispanocolonial organizadas para el culto cristiano y la práctica de la ayuda social a sus miembros y otras personas, mediante la caridad y atención cristiana, asistencia y apoyo económico, y la realización de la beneficencia corporativa. Como asociaciones de carácter religioso y lugares comunes de sociabilidad en una sociedad jerárquica y estamental en situación de dominación colonial, en las cofradías se desarrollaron procesos financieros de tipo mercantil, de formación

\footnotetext{
${ }^{1}$ La devoción por las almas benditas del Purgatorio se reconoce en conjunto con la existencia y éxito del Purgatorio, proceso que se sitúa entre los siglos XVI y XVIII. Le Goff, Jacques. 1981. El nacimiento del purgatorio. Madrid: Taurus.

${ }^{2}$ En los reinos españoles peninsulares de los siglos XVI y XVII, el culto de las Ánimas Benditas del Purgatorio permite, además de la intersección sobrenatural para con los vivos, alcanzar objetivos fiscales (por las bulas), y de conversión. Tausiet Carlés, María. 2005. «Gritos del más allá. La defensa del purgatorio en la España de la Contrarreforma». Hispania Sacra 57: 81-108.
} 
de identidades étnicas y de género, y de construcción o reforzamiento de los sistemas de autoridad y gobierno hispano, indígena y de las castas. ${ }^{3}$

La cofradía que se describe y analiza en este artículo, se encuentra en la ciudad de San Salvador de Jujuy, ${ }_{4}$ y al igual que la mayoría de las cofradías que funcionan en esta y otras ciudades de la región en el período colonial, se trata de una asociación de tipo religiosa o como se las conoce en Nueva España: hermandades religiosas. 5

Desde el mismo momento de la fundación de la ciudad de San Salvador de Jujuy en 1593, se constituyen cofradías religiosas en el casco urbano y en el pueblo indígena de Humahuaca, como asociaciones que carecen de cuerpo de autoridades jerárquicas, constituciones o patentes eclesiásticas, que ameriten reconocimiento estatal, y de escasos y esporádicos ingresos de bienes y recursos. Situación que se mantiene durante el siglo XVII. ${ }^{6}$

En el XVIII cambia el panorama, porque las cofradías se consolidan socialmente al recibir donaciones y limosnas regulares de las personas que se adscri-

\footnotetext{
${ }^{3}$ El estudio de las cofradías religiosas, ha facilitado el conocimiento de los procesos de dominación colonial y adaptación en resistencia, etnicidad, creación, y reforzamiento de la identidad, el rol y las características de las instituciones financieras eclesiásticas en el mercantilismo colonial, y el empoderamiento de las castas de negros, mulatos, indios y mujeres. Bazarte Martínez, Alicia. 1989. Las cofradías de españoles en la ciudad de México (1526-1869). México: Universidad Autónoma Metropolitana. Bechtloff, Dagmar. 1996. Las cofradías de Michoacán durante la época colonial. La religión y su relación política y económica en una sociedad intercultural. México: El Colegio de Michoacán. Celestino, Olinda y Meyers, Albert. 1981. Las cofradías en el Perú: región central. Frankfurt: Verlag Klaus Dieter Vervuert. Diez Hurtado, Alejandro. 1994. Fiestas y cofradias. Asociaciones religiosas e integración en la historia de la comunidad de Sechura (siglos XVII al XX). Piura: CIPCA. Luque Alcaide, Elisa. 1995. La cofradía de Aránzazu de México (1681-1799). Pamplona: Ediciones Eunate. Platt, Tristán. 1989. Los guerreros de Cristo. Cofradía, misa solar y guerra regenerativa en una doctrina Macha (siglos XVIII-XX). La Paz: ASUR-plural. Valenzuela Márquez, Jaime. 2010. «Devociones de inmigrantes. Indígenas andinos y plurietnicidad urbana en la conformación de cofradías coloniales (Santiago de Chile, siglo XVII)». Historia 43-1: 203-244.

${ }^{4}$ En los siglos XVI y XVII, la ciudad de Jujuy está en una región constituida por la dinámica de la minería potosina y política de Charcas, por eso se dice que ella y las otras ciudades de la gobernación se encuentran «al sur de Charcas». Situación que cambia en el siglo XVIII, al adquirir paulatina importancia las ciudades de Salta, Tucumán, Córdoba y Buenos Aires, y Jujuy pasa a adscribirse a la región de Tucumán o Salta del Tucumán como se denomina a la Intendencia. Assadourian, Carlos Sempat. 1983. El sistema de la Economía Colonial. El mercado interior. Regiones y espacio económico. México: Editorial Nueva Imagen.

${ }^{5}$ En Jujuy no se encuentran cofradías gremiales, distintas de las religiosas por el sentido asistencialista que tienen en los reinos españoles e indianos. Benítez Bolorinos, Manuel. 1998. Las cofradías medievales en el Reino de Valencia (1329-1458). Alicante: Publicaciones de la Universidad de Alicante. Paniagua Pérez, Jesús. 1995. «Cofradías limeñas: San Eloy y la Misericordia (1597-1733)». Anиario de Estudios Americanos LII-1: 13-35.

${ }^{6}$ Bruno, Cayetano. 1968. Historia de la Iglesia en la Argentina. Buenos Aires: Editorial Don Bosco, tomos III a VII.
} 
ben a ellas, las que además, se organizan en sistemas de cargos de gobierno y obtienen el reconocimiento estatal de funcionamiento, en algunos de los tres templos de la ciudad (a veces con capilla propia). De esta manera, surgen cofradías en el casco urbano de la ciudad, en el anexo rural del curato rectoral, y en casi todos los curatos rurales del ejido y dehesa. Con el culto organizado por un cuerpo de oficiales que recolectan y administran los bienes y recursos donados por los cofrades y autoridades, las cofradías disponen de fondos para cumplir con las obligaciones religiosas, de atención caritativa, fomento y administración económica que las caracteriza. ${ }^{7}$

La división entre cofradías urbanas y rurales, es algo que puede establecerse en las cofradías religiosas de Jujuy. ${ }^{8}$ En las urbanas se atiende el culto religioso, se práctica la piedad y religiosidad cristiana relacionada con la sepultura y el entierro, se atiende social y caritativamente, y se provee financieramente el mercantilismo de giro local y regional. ${ }^{9}$ En cuanto a las rurales, sin dejar de realizarse estas tareas, también se controlan recursos comunitarios sustraídos al control hispano de curas doctrineros, encomenderos y hacendados, ${ }^{10}$ y se desarrollan de procesos de constitución y/o reforzamiento de la autoridad e identidad indígena. ${ }^{11}$

La cofradía de las Ánimas Benditas del Purgatorio de Jujuy, tiene sede en el templo de la iglesia matriz de la ciudad, que también alberga asociaciones que comienzan como organizaciones cofradiales en torno a la fiesta de una advoca-

\footnotetext{
${ }^{7}$ Cuando una cofradía religiosa está completamente organizada, desarrolla un conjunto variado y múltiple de tareas. Garland Ponce, Beatriz. 1994. «Las cofradías en Lima durante la colonia. Una primera aproximación», en Gabriela Ramos (comp.) La venida del reino. Religión, evangelización y cultura en América, Siglos XVI-XX: 199-228. Cuzco: Centro de Estudios Regionales Andinos «Bartolomé de Las Casas».

${ }^{8}$ Esta es una clasificación que sirve para el contexto regional andino de estudio. Acerca de otras clasificaciones, puede consultarse el estudio general de Rumeu de Armas, Antonio. 1981. Historia de la previsión social en España. Cofradías - gremios - hermandades - montepíos. Barcelona: Ediciones El Albir. O el estudio específico de González Fassani, Ana M. 2005. «¿Qué entendemos por cofradía colonial?»: una aproximación a un marco teórico para su estudio», en Hilda R. Zapico (coordinadora) De prácticas, comportamiento y formas de representación social en Buenos Aires, siglo XVII y XIX: 225-261. Bahía Blanca: ediUNS.

${ }^{9}$ La ciudad de Jujuy esta en el siglo XVIII completamente incluida en el mercantilismo de regional, gracias a la instalación de la aduana en 1690 y la utilización de las tierras locales para la invernada y engorde del ganado vacuno y mular que transita hacia la minería potosina. Santamaría, Daniel J. 1999. «Mercaderes, tenderos y prestamistas. La mercantilización de la economía jujeña (1690-1730)». Anuario del IEHS 14: 437-469.

${ }^{10}$ Zanolli, Carlos y Alonso, Claudia. 2004. «Santa Bárbara, una cofradía de indios en San Antonio de Humahuaca (1713-1785)». Anuario Historia Regional de las Fronteras IX: 87-109.

${ }^{11}$ La reconstitución identitaria étnica indígena, también puede darse en las cofradías urbanas de indios. Cruz, Enrique N. 2007. «Una cofradía urbana de indios a fines de la colonia: San Pedro de Naturales (Jujuy - Río de la Plata)». Revista Andina 44: 227-248.
}

Hispania Sacra, LXIV

130, julio-diciembre 2012, 721-736, ISSN: 0018-215X, doi: 10.3989/hs.2012.021 
ción, como Nuestra Señora del Carmen y San Pedro de Naturales, o como asociaciones de feligreses para administrar ingresos regulares de mandas forzosas, el caso de las Ánimas, Redención de Cautivos Cristianos y Santos Lugares de Jerusalén. Además de las cofradías religiosas con sede en el templo de la matriz, en la ciudad de Jujuy funcionan otras en el templo del convento franciscano, en el de La Merced y en el oratorio de San Roque.

Es difícil precisar el número exacto de las cofradías de Jujuy, porque como se señalo respecto de las cofradías de la matriz, estas asociaciones aparecen y desaparecen de acuerdo al desarrollo de los afanes asociativos urbanos relacionados al control y administración de los bienes y recursos, la dadivosidad, preocupación y celo cristiano y financiero de las autoridades, y otras cuestiones. Aún así, puede afirmarse que entre fines del siglo XVII y primeras décadas del XIX en que registra su funcionamiento la cofradía de las Ánimas, existen otras doce cofradías religiosas en el casco urbano y el anexo rural del rectoral, a las que se deben sumar cinco cofradías en el curato de Humahuaca, y por lo menos una o dos cofradías en cada cabecera de los curatos de Tilcara, Casabindo y Cochinoca, Yavi y Santa Catalina. ${ }^{12}$

Podemos conocer el funcionamiento del las cofradías religiosas, gracias a distintos tipos de registros documentales. Por ejemplo, la cofradía urbana de Nuestra Señora del Carmen, tuvo un típico libro de cofradía de constituciones, registro de los cofrades, donaciones, pagos y limosnas recibidas, y recopilación de las gracias e indulgencias que reciben los esclavos de la virgen que cumplen con las pautas de la devoción. ${ }^{13}$ Similar es el registro que ha quedado de la Archicofradía de San Benito de Palermo de negros y mulatos..$^{14}$ En cambio, de la cofradía del Santísimo Sacramento ha quedado un libro que consigna solo la adscripción de los cofrades con los pagos y limosnas y la elección de las autoridades, con la rendición contable correspondiente al período de ejercicio..$^{15}$ Menos información es la que aporta el libro de la cofradía de San Pedro de Naturales, en este caso, se trata del «Libro de colecturía», como se llama al registro de los bienes y recursos donados y entregados como limosnas cuando se registran y eligen autoridades. ${ }^{16}$

12 Cruz, Enrique N. 1997. «De igualdades y desigualdades: Cofradías en el Jujuy colonial». Anuario del IEHS 12: 293-305.

13 Archivo del Obispado de Jujuy (en adelante AOJ), Libro de la cofradía de Nuestra Señora del Carmen, carpeta 27, legajo 12, (10-1).

${ }^{14}$ Archivo del Convento de San Francisco de Jujuy, Libro Mayor de Constituciones y Cuentas de la Archicofradía de San Benito de Palermo, Jujuy, 1776-1859.

15 AOJ, Libro de la cofradía del Santísimo Sacramento, Jujuy, carpeta 26, legajo 10 (9-1).

16 AOJ, Libro de colecturía de la cofradía de San Pedro de naturales, Libro de Matrimonios, Catedral (1693-1836), No 4, Naturales. 
De otras cofradías no ha quedado el registro del libro para conocer su funcionamiento, ya fuere porque no contó con uno, se extravió, quedo en manos de las autoridades sin ser depositado en el templo sede de la asociación, o porque no lo preciso, como parece ser el caso de la cofradía de las Ánimas. Esta cofradía es una asociación que figura entre las primeras de la ciudad de Jujuy (siglo $\mathrm{XVI}$ ), y funciona hasta por lo menos mediados del siglo XIX. No hay registro del libro de la cofradía, si lo tuvo, pero si existen referencias en testamentos, inventarios de bienes y libros de fábrica, que dan cuenta del culto y devoción a las Ánimas y la organización cofraderil, con bienes y recursos que se administran, porque son importantes para el desarrollo mercantil de la ciudad. Lo que además, da lugar, al cuerpo de autoridades a través del cual la cofradía desarrolla tareas de atención social y caridad cristiana relacionadas con la sepultura y entierro. ${ }^{17}$

\section{LAS MANDAS FORZOSAS Y LAS COFRADÍAS}

Las mandas forzosas son, donaciones generalmente en efectivo, que se dejan de manera compulsiva por costumbre cristiana en testamentos y codicilos para una advocación, por las gracias espirituales e indulgencias que otorgan al alma del difunto y otros beneficios terrenales..$^{18}$ La extendida práctica social que tienen en los testamentos de Jujuy del siglo XVIII, permite la acumulación de bienes y recursos con los que cumplir la primera condición para que la devoción se constituya en cofradía: «el noble fin» de dar sepultura y entierro a las personas, sean o no cofrades. ${ }^{19}$

Las mandas forzosas son pagos que a título de limosna se hacen con una parte del patrimonio del difunto, por regla tradicional un quinto, fuere que así lo haya dispuesto o lo dispongan los albaceas. Las contribuciones individuales a las mandas varían en cada lugar: en Buenos Aires la costumbre indica que debe ser de dos a ciento sesenta reales, ${ }^{20}$ en Jujuy de medio a cuatro reales, excepcio-

\footnotetext{
${ }^{17}$ Base de datos de mandas forzosas y donaciones específicas para la cofradía de las Ánimas Benditas del Purgatorio de Jujuy. Muestra de 345 testamentos, codicilos e inventarios de bienes (1690 a 1810). El resumen de la base de datos en: Cruz, Enrique N. 2003. Cofradías, Montepíos y Hospitales en la sociedad Jujeña del siglo XVIII. Sevilla: Tesis Doctoral Universidad de Sevilla.

18 Alcalá Moreno, Ildefonso. 2005. «Las devociones religiosas en Sierra Mágina a través de las mandas testamentarías». Sumuntán. Revista de Estudios sobre Sierra Mágina 22: 167-182.

${ }^{19}$ Bazarte Martínez, Alicia y García Ayluardo, Clara. 2001. Los costos de la salvación. Las cofradías y la ciudad de México (siglos XVI al XIX): 54-66. México: Instituto Politécnico Nacional y Archivo General de la Nación.

${ }^{20}$ Socolow, Susan M. 1991. Los mercaderes del Buenos Aires virreinal: familias y comercio: 127. Buenos Aires: Ediciones de la Flor.
} 
nalmente un peso, y en algunas ciudades de Nueva España, lo usual es que se dejen siete reales. ${ }^{21}$

Las mandas forzosas pueden agruparse en una sola, o distinguirse entre la de Cautivos Cristianos, Lugares Sagrados de Jerusalén, Sagrado Sacramento y Santa Cruzada. En los testamentos e inventarios de bienes analizados, además de estas, figura como manda la limosna para las Ánimas Benditas del Purgatorio. El $62 \%$ de las personas de la muestra de testamentos disponen de manera personal o por albacea el pago de las mandas forzosas, ordenando taxativamente en algunos casos, el monto preciso, para que no se constituya en «costumbre», y sólo se paguen «por única vez».

\section{Mandas forzosas dispuestas personalmente o por albacea en Jujuy (1690-1810)} MANDAS FORZOSAS
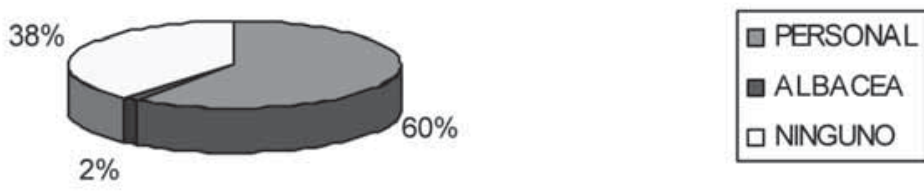

Desde el siglo XVII e incrementándose paulatinamente en el XVIII, los pagos que se dejan para las mandas forzosas generan un monto de dinero que, en una sociedad siempre necesitada de efectivo como la de Jujuy, se constituye en un «capital» que debe ser administrado. Las devociones de las mandas de la Redención de Cautivos Cristianos y Santos Lugares de Jerusalén, tienen en los conventos de los mercedarios y franciscanos respectivamente, los cuerpos religiosos que organizan y administran las donaciones en respectivas cofradías. Las Ánimas Benditas del Purgatorio y el Santísimo Sacramento con sede en el templo de la matriz, se organizan de manera más laica, con cuerpo de autoridades, reclutamiento de cofrades y administración de bienes. En los cuatro casos e independientemente del mayor o menor control eclesiástico, lo que se busca con los dineros y bienes de las mandas, es asegurar la reproducción del «capital espiritual» generado por las donaciones y limosnas que se reciben. ${ }^{22}$

${ }^{21}$ Sola Corbacho, Juan C. 1999. «Los comerciantes mexicanos frente a la muerte (1765-1800)»: 185. Revista Complutense de Historia de América 25.

${ }^{22}$ Lavrin, Asunción. 1998. «Cofradías novohispanas: economías material y espiritual», en LópezCano, María del Pilar, Von Wobeser, Gisela y Muñoz Correa, Juan (coord.) Cofradías, capellanías y obras pías en América Colonial: 49-50. México: Universidad Nacional Autónoma de México. 
De las cinco asociaciones constituidas a partir de las mandas forzosas, en el siglo XIX solo queda el registro de funcionamiento de la cofradía de las Ánimas Benditas del Purgatorio y del Santísimo Sacramento del Altar, ${ }^{23}$ lo que tal vez tuvo que ver con que desarrollan una más independiente organización cofraderil.

\section{La Cofradía de las Ánimas Benditas del PuRgatorio}

Las donaciones y pagos que se realizan para las Ánimas Benditas del Purgatorio, se instauran como una de las mandas forzosas ineludibles por la difusión que alcanza en la modernidad la idea del infierno y la corrección temporal del purgatorio.$^{24}$ La promoción del culto a las Ánimas y la pauta de lo que los feligreses deben seguir, es estipulada institucionalmente por el tercer Sínodo de 1607 del Tucumán, que determina en el capítulo $14^{\circ}$ que se hagan plegaria por las Ánimas:

«Santa provechosa cosa es hacer oración por los difuntos, dice la sagrada escritura, y costumbre muy loada y usada en la santa iglesia que todas las noches a media hora de noche, mas o menos, se tañan las campanas de las catedrales y parroquiales para ese efecto, y queremos y mandamos se haga así en todo nuestro obispado y los sacristanes tengan este oficio muy a cargo, y hagan la plegaria por el orden que dieren a nuestros vicarios». 25

A pesar de la pauta institucional, en el siglo XVII no hay registros documentales del culto y devoción a las Ánimas Benditas del Purgatorio en Jujuy, sólo se han ubicado los bienes y recursos entregados como limosna de manera esporádica a las mandas. La situación cambia en el siglo siguiente, porque se regulariza el aporte de la limosna para las Ánimas, y se establece así, la organización y administración de los bienes y recursos por medio de la elección periódica de autoridades que determinan y organizan los objetivos y realizan las tareas que incumben a la asociación.

\footnotetext{
${ }^{23}$ En 1828 el presbítero de Jujuy Santiago Solano de Espinosa, deja en el testamento a las cofradías del Santísimo Sacramento y de las Ánimas Benditas del Purgatorio «4 reales, con la intención de que hago de ganar las indulgencias concedidas a las mandas forzosas». AOJ, Testamento del presbítero Santiago Solano de Espinosa, Jujuy, 1828, carpeta 16, legajo 12.

${ }^{24}$ Minois, Georges. 1994. Historia de los Infiernos. Barcelona: Paidós. Le Goff, Jacques. 1981. El nacimiento del purgatorio. Madrid: Taurus.

25 Toscano, Jaime. 1906. El primitivo obispado del Tucumán y la iglesia de Salta: 606. Buenos Aires: Imprenta de M. Biedma e hijo.
} 


\section{El registro cofraderil}

No se ha encontrado ningún tipo de registro cofraderil del tipo libro mayor, de colecturía, de constituciones o cualquier otro de la cofradía de las Ánimas, por lo que las ceremonias, relaciones sociales, constituciones, patentes e indulgencias especiales de la cofradía no las conocemos. Los testamentos e inventarios de bienes de los que se extrajo la mayor parte de la información sobre la asociación, tampoco mencionan nada al respecto. Sólo un documento de 1724 sobre las donaciones y rogativas a realizar en la iglesia matriz de Jujuy, por las «entradas militares al Chaco», ${ }^{26}$ señala que el «18 del mes de septiembre de 1724 se hace la misa mayor de las Benditas Ánimas del Purgatorio en la iglesia matriz de Jujuy». ${ }^{27}$

Por la ausencia del libro de la cofradía de las Ánimas, puede inferirse que no existió, que la asociación no se constituyo como tal, o que por las características de funcionamiento regional y local no necesito uno. Me inclino por la tercera opción, pues si bien no existe el libro que confirme su existencia, las referencias encontradas de limosnas, donaciones en bienes y recursos, pautas establecidas acerca de la elección y denominación de las autoridades, y la especificación de las obligaciones de los cofrades, dan a entender que si funciono como cofradía, pero que no preciso un libro de registro, por el poco desarrollo del culto social a las Ánimas en la ciudad de Jujuy.

\section{Autoridades}

Las autoridades de las Ánimas Benditas del Purgatorio de Jujuy no constituyen un cuerpo jerárquico, periódico e institucional como en otras cofradías de la región..$^{28}$ Se eligen al efecto sin regularidad electiva ni periódica, y sólo apa-

\footnotetext{
${ }^{26}$ Las «entradas al Chaco» son campañas militares realizadas desde el siglo XVII por los hispanos de las ciudades del Tucumán, con el objetivo principal de proveer de mano de obra servil y esclava al mercado laboral. Vitar, Beatriz. 1997. Guerra y misiones en la frontera chaqueña del Tucumán (17001767). Madrid: Consejo Superior de Investigaciones Científicas. Doucet, Gastón. 1988. «Sobre cautivos de guerra y esclavos indios en el Tucumán. Notas en torno a un fichero documental salteño del siglo XVIII». Revista de Historia del Derecho 16: 59-152.

${ }^{27}$ AOJ, Auto del obispado sobre donaciones y rogativas para entradas al Chaco, Jujuy, 7 de julio de 1735 , carpeta 11, legajo 48 .

${ }^{28} \mathrm{Sin}$ importar el tamaño de las ciudades, la estructura y grado de complejidad del cuadro de gobierno de una cofradía puede ser mayor o menor. Algunas de Lima son gobernadas por un cabildo de autoridades: padre capellán, mayordomo primero y segundo, diputados, alférez, procurador, contador, tesorero, prioste o mayoral, y hermanos veinticuatro. Garland Ponce, Beatriz. 1994. «Las cofradías en Lima durante la colonia. Una primera aproximación», en Gabriela Ramos (comp.) La venida del reino. Religión, evangelización y cultura en América, Siglos XVI-XX: 212-213. Cuzco: Centro de Estudios
} 
recen cuando se debe tomar una disposición atinente al manejo de bienes y recursos de la cofradía, o decidir sobre cuestiones financieras o administrativas. Son los Mayordomos de las Ánimas, que firman y expiden recibos por las mandas forzosas pagadas por disposición testamentaria del difunto o albacea.

En algunos de los recibos documentados, se menciona como autoridad al «mayordomo más antiguo», 29 sin especificar cuál es la diferencia con el otro mayordomo. Así se consigna que en 1752, se desempeña como «mayordomo más antiguo», el patricio local general Agustín de Leysa. Hacendado y activo comerciante que, entre otras cosas, construye un molino de trigo y tiene fábrica de ladrillos de las que probablemente saca los materiales para reparar el templo de la iglesia matriz, de la que también es mayordomo de fábrica, al igual que es mayordomo del convento de la Merced, al que le construye un retablo nuevo tasado en 3000 pesos..$^{30}$

Sobre las autoridades de la cofradía, no se conoce mucho más, salvo lo que menciona la copia de una orden del obispado del Tucumán recibida en la matriz de Jujuy antes de 1750, en la que se dispone que las cuestiones económicas y religiosas de la cofradía de las Ánimas, se traten en «Junta general» de los principales cofrades y los capellanes. Al tener la cofradía sede de funcionamiento en la iglesia matriz de la ciudad, los capellanes son los mismos presbíteros, a los que se suman otros seis mayordomos que se sortean anualmente. ${ }^{31}$

A comienzos del siglo XIX, desaparece de los registros documentales analizados (recibos de las mandas), el mayordomo y el mayordomo más antiguo, y no se sabe si la Junta general de los principales cofrades y capellanes funcionó o no. Lo que si menciona en algunos recibos de las mandas, son dos «hermanos mayores» de carácter vitalicio con la obligación principal de recolectar limosnas para realizar los sufragios por las Ánimas, y costear de su peculio la «fun-

\footnotetext{
Regionales Andinos «Bartolomé de Las Casas». La cofradía de San Pedro de Naturales de Jujuy, también exhibe un cuadro jerárquico amplio de autoridades: procurador perpetuo, mayordomo mayor, alférez mayor y menor, ayudante mayor y del mayordomo, diputado del campo y de la ciudad, alférez y ayudantes de alférez. Cruz, Enrique N. 2007. «Una cofradía urbana de indios a fines de la colonia: San Pedro de Naturales (Jujuy - Río de la Plata)». Revista Andina 44: 227-248.

${ }^{29}$ Archivo de Tribunales de Jujuy (en adelante ATJ), Testamento e inventario de bienes de Lorenzo Valero, Jujuy, 1798/1800, carpeta 65, legajo 2057.

${ }^{30}$ Agustín de Leysa es también autoridad política: en 1749 se desempeña como alcalde ordinario de $1^{\circ}$ voto de la sala capitular de Jujuy. Zenarruza, Jorge G. C. 1991. Los Vascos en América. Investigación sobre asentamientos vascos en el territorio argentino, siglo XVI a XIX, Tomo I: 479-485. Buenos Aires: edición del autor.

${ }^{31}$ AOJ, Copia y resolución del obispado del Tucumán acerca de la distribución de las limosnas para el ornamento de la cofradía de las benditas ánimas del purgatorio, Jujuy, 1750-1751, carpeta 28, legajo 11 (11-1).
} 
ción de aniversario o la conclusión del novenario», tal como lo dispone en un despacho de la matriz, el cura y vicario doctor Manuel José de Leaniz. ${ }^{32}$

Por las tareas que a título de servicios como administradores temporales prestan a la cofradía, los mayordomos y hermanos mayores de las Ánimas reciben entierro y sepultura especial en el templo de la iglesia matriz, y misas cantadas especiales de los curas párrocos capellanes de la cofradía. ${ }^{33} \mathrm{~A}$ la diferenciación cofraderil, hace alusión el sargento mayor y vecino de la plaza de Jujuy Domingo González, al disponer en el testamento, que la sepultura se haga en la iglesia matriz «donde esta enterrado mi padre, junto a la tabla de los mayordomos de las Benditas Ánimas del Purgatorio».34

\section{Bienes y recursos}

Los bienes y recursos con los que cuenta la cofradía de las Ánimas, son las donaciones de propiedades rurales, como la hacienda en la Puna de Jujuy puesta a censo inmediatamente en $1652 .{ }^{35}$ Solares y fracciones de propiedades inmuebles o terrenos ubicados en el mismo casco urbano de la ciudad, que también se venden para poner el dinero a censo en el circuito financiero mercantil local, como figura en los protocolos del escribano público de la sala capitular en 1810, que autoriza la solicitud para extender la escritura de venta de un sitio perteneciente a la cofradía de las Ánimas a Antonio Catacata en 50 pesos, «con consentimiento de los hermanos de dicha cofradía y de los señores curas de esta Iglesia Matriz como capellanes que son de ella, de 60 varas de frente y de fondo, ubicada hasta la barranca del Río Grande». ${ }^{36}$

Otro ingreso de dinero de la cofradía, proviene de las mandas forzosas, que por testamento o albaceazgo se instituyen para las Ánimas. Las mandas dis-

32 AOJ, Disposiciones del doctor Manuel José de Leaniz, Jujuy, 2 de septiembre de 1806, carpeta 27, legajo $5(10-1)$.

${ }^{33}$ La prevalencia en los entierros y sepultura de los mayordomos, es una costumbre respetada en casi todas las cofradías indianas. En la ciudad vecina de Córdoba del Tucumán, el maestro Diego Fernández de Sotomayor pide en 1661, sepultura en el mismo altar de las ánimas de la iglesia mayor por haber sido mayordomo. Martínez de Sánchez, Ana María. 2005. «La resurrección de los muertos. Significado del espacio sepulcral»: 119. Hispania Sacra 57.

${ }^{34}$ ATJ, Testamento de Domingo González, Jujuy, 1768, carpeta 44, legajo 1456.

${ }^{35}$ Hacienda de Aicate en la Puna de Jujuy. Vergara, Miguel A. 1942. Estudios sobre historia eclesiástica de Jujuy: 282. Tucumán: Universidad Nacional de Tucumán.

${ }^{36}$ Los que firman el pedido y la venta posterior son los capellanes de la cofradía y presbíteros de la iglesia matriz, y los «hermanos de ella Tomas de Martierena, Pedro Antonio de Hereña, Ángel Antonio de la Barcena, Antonio Ramos, y Manuel Francisco de Basterra». ATJ, Boletos de escrituras del escribano público del cabildo José Gundian, Jujuy, 1800-1802, carpeta 66, legajo 2107. 
puestas, reconocidas y pagadas en Jujuy, son de ocho ${ }^{37}$ y dieciséis reales, ${ }^{38}$ y lo más usual es que sean de cuatro y dos reales. ${ }^{39}$

Los réditos de capellanías también son un aporte de dinero para la cofradía. Algunas tienen sede en el convento franciscano y son administradas en conjunto con la cofradía de las Ánimas, por instituirse en beneficio del alma de un particular. Es el caso del mediano comerciante con tienda Andrés Mendoza, que instituye en 1710 una de 700 pesos de principal junto a otra de 2000 pesos. También hay capellanías que son administradas exclusivamente por las Ánimas, como la que reconoce el comerciante Bartolomé Domínguez en 1768 de 600 pesos, aporte que hace a la asociación junto a 50 libras de cera «en consideración a su alma». ${ }^{40}$ Las fundaciones para las Ánimas administradas por la cofradía, son para favorecer al alma del que instituye el capital, y también para la de los padres, cónyuges y parientes en general. Como lo dispone el 4 de marzo de 1786 Marcela Fernández, vecina de la ciudad de Jujuy, que pone a censo unas casas de «mi habitación para sufragio de las Benditas Animas, mía y de mis padres y parientes». La casa se tasa en 600 pesos, y linda con el solar propiedad de las Ánimas hacia el naciente de la ciudad también a censo.41

El dinero que administra la cofradía, puede prestarse a particulares. En 1716 se consigna en el testamento de Manuel Álvarez de Losada, que el capitán Domingo de Gareca adeuda a la cofradía de las Ánimas 170 pesos, y que de manera similar, el mulato libre Joaquín de Aguirre le debe 70 pesos. ${ }^{42}$

Para aumentar los ingresos de la cofradía, se pueden alquilar los ornamentos, para el entierro y sepultura de personas que no pertenecen a la asociación. La testamentaria realizada luego de la muerte de Domingo López Morardín en 1752, reconoce el pago de «12 reales dados al mayordomo de las Ánimas por los candeleros de la cofradía que sirvieron en el entierro». ${ }^{43}$ En 1767 , los alba-

${ }^{37}$ ATJ, Testamentaria de Domingo López Morardín, Jujuy, 1752, carpeta 38, legajo 1248. Testamento de Francisco Antonio de Azebey, Jujuy, 1790, carpeta 61, legajo 1944.

38 ATJ, Inventario y tasación de los bienes de Catalina Zebreros, Jujuy, 1793, carpeta 62, legajo 1976.

${ }^{39}$ AOJ, Testamento de Santiago Solano de Espinosa, Jujuy, 1828, carpeta 16, legajo 12. ATJ, Testamento de Bárbara Martínez de Iriarte, Jujuy, 1761, carpeta 41, legajo 1374. Testamento de Felipe Ruiz Cabrera, Jujuy, 1790, carpeta 61, legajo 1944.

40 ATJ, Testamento de Bartolomé Domínguez, Jujuy, 1738, carpeta 38, legajo 1139.

${ }^{41}$ AOJ, Expediente de la capellanía a favor de las benditas ánimas en Iglesia matriz de Jujuy fundada por Marcela Fernández, 21 de febrero de 1794, Jujuy, carpeta 1, legajo 9.

42 ATJ, Inventario de bienes de Andrés de Mendoza, Jujuy, 1710, carpeta 27, legajo 837. Testamento de Bartolomé Domínguez, Jujuy, 1738, carpeta 38, legajo 1139. Testamento de Manuel Álvarez de Lozada, Jujuy, 1716, carpeta 27, legajo 883. Pleito por carta de capellanía fundada a favor de las benditas ánimas del purgatorio de 1000 pesos de principal, Jujuy, 1774, carpeta 49, legajo 1589.

${ }^{43}$ ATJ, Testamentaria de Domingo López Morardin, Jujuy, 1752, carpeta 38, legajo 1248. 
ceas del cura de Humahuaca doctor Pedro José de Sosa, reconocen en el inventario de bienes que por derechos de funeral se pagaron 962 pesos, discriminados de la manera siguiente: por el ataúd 15 pesos, por abrir la sepultura 12 reales, y por el alquiler de los candeleros, hacheros y manta de la cofradía de las Ánimas 3 pesos. ${ }^{44}$

Esta manera de sumar recursos para la cofradía, es institucionalizada por las autoridades eclesiásticas del Tucumán en 1750, al disponer sobre la distribución de las limosnas que «sobraren para las Ánimas», ordenando que el destino tiene que ser la provisión de ornamentos para la cofradía, que llegado el caso de solicitarse el ornamento para alguna función particular y «no siendo hermana de esta santa cofradía, contribuyan lo competente para aumento de ella».45

\section{Atención social y servicios}

Los bienes y recursos que dan lugar a la organización del culto a las Ánimas en cofradía religiosa, se destinan a la realización de misas para las almas de los cofrades y particulares difuntos, adornos para el culto, ${ }^{46}$ imposición de censos y préstamos de dinero en efectivo a los cofrades y autoridades ${ }^{47}$ Los que se benefician de los bienes y recursos pertenecen al patriciado local que gobierna la cofradía, y otras personas alejadas de ese grupo, como el mulato que recibe un pequeño monto de dinero que devuelve en trabajo.48

Respecto de los préstamos de la cofradía, aunque se reconoce que la Iglesia desarrolla la estrategia de ornamentar las devociones como medio para atesorar

\footnotetext{
${ }^{44}$ ATJ, Testamento e inventario de bienes de Pedro José de Sosa, Jujuy, 1767, carpeta 44, legajo 1460.

${ }^{45}$ AOJ, Copia y resolución del obispado del Tucumán acerca de la distribución de las limosnas para el ornamento de la cofradía de las Benditas Ánimas del Purgatorio, Jujuy, 1750-1751, carpeta 28, legajo 11 (11-1).

46 «Una docena de candeleros de palo plateados que se compraron para las ánimas, cuios devotos dieron 9 pesos y la iglesia otros, 1741». AOJ, Libro de bautismos de naturales, catedral, bautismos, matrimonios y defunciones y de colecturía, Jujuy, 1741-1758.

${ }^{47}$ En el registro de escrituras del cabildo de 1794, figura que el vecino y capitán graduado Tomas de Martierena, reconoce 600 pesos de censo redimible perteneciente al beneficio de las Ánimas, impuestos sobre las tierras y molinos de su propiedad. Cuando el molino se derrumba, y mientras lo arreglan el propietario y los curas de la matriz, el censo se impone sobre una casa en la plaza que tiene otra capellanía de la cofradía. ATJ, Registro protocolos de escrituras, Jujuy, 1794, carpeta 63, legajo 2001.

${ }^{48}$ En el testamento de Manuel Álvarez de Lozada, figura que el capitán Domingo de Gareca debe a la cofradía de las Ánimas 170 pesos, y que Joaquín de Aguirre, mulato libre, le debe 70 pesos que se obliga a pagar el comerciante de géneros Miguel de Otaiza,con 28 varas de ropa de la tierra a cinco pesos, los «que a esta cuenta se le escalfan de su salario al dicho Joaquín de Aguirre que sirve al presente al dicho Miguel de Otaiza». ATJ, Testamento de Manuel Álvarez de Lozada, Jujuy, 1716, carpeta 27, legajo 883 .
} 
en bienes que no se devalúan y que luego pone a circular en el giro mercantil lo$\mathrm{cal}^{49}$ las autoridades eclesiásticas locales ponen límites. La misma disposición del obispado del Tucumán de 1750 que señala la conveniencia de alquilar los bienes del culto sepulcral y mortuorio a los que no pertenecen a la asociación, previene que los ornamentos y adornos no pueden utilizarse para otra cosa que no sea la de proveer a las necesidades del ceremonial religioso de la cofradía. ${ }^{50}$

\section{CONCLUSIÓN}

La cofradía religiosa urbana de las Ánimas Benditas del Purgatorio de Jujuy, conocida gracias a los testamentos e inventarios de bienes, referencias en censos y capellanías, recibos de pago por las mandas forzosas, reconocimientos de acreencias, y disposiciones del obispado reproducidas por la iglesia matriz de Jujuy. Por encima de cuestiones espirituales y ultraterrenas, prestó especial atención a dos cuestiones terrenas de los cofrades y no cofrades: la asistencia social caritativa y religiosa en la sepultura y entierro, y el préstamo financiero para el nivel social intermedio entre el patriciado de giro regional y la plebe urbana.

\section{BIBLIOGRAFÍA}

Alcalá Moreno, Ildefonso. 2005. «Las devociones religiosas en Sierra Mágina a través de las mandas testamentarías». Sumuntán. Revista de Estudios sobre Sierra Mágina 22: 167-182.

Assadourian, Carlos Sempat. 1983. El sistema de la Economía Colonial. El mercado interior. Regiones y espacio económico. México: Editorial Nueva Imagen.

Bazarte Martínez, Alicia y García Ayluardo, Clara. 2001. Los costos de la salvación. Las cofradías y la ciudad de México (siglos XVI al XIX). México: Instituto Politécnico Nacional y Archivo General de la Nación.

Bazarte Martínez, Alicia. 1989. Las cofradías de españoles en la ciudad de México (1526-1869). México: Universidad Autónoma Metropolitana.

Bechtloff, Dagmar. 1996. Las cofradías de Michoacán durante la época colonial. La religión y su relación política y económica en una sociedad intercultural. México: El Colegio de Michoacán.

\footnotetext{
49 Von Wobeser, Gisela. 1994. El crédito eclesiástico en la Nueva España. México: Universidad Nacional Autónoma de México.

${ }^{50}$ AOJ, Copia y resolución del obispado del Tucumán acerca de la distribución de las limosnas para el ornamento de la cofradía de las Benditas Ánimas del Purgatorio, Jujuy, 1750-1751, carpeta 28, legajo 11 (11-1).
} 
Benítez Bolorinos, Manuel. 1998. Las cofradías medievales en el Reino de Valencia (1329-1458). Alicante: Publicaciones de la Universidad de Alicante.

Bruno, Cayetano. 1968. Historia de la Iglesia en la Argentina. Buenos Aires: Editorial Don Bosco, tomos III a VII.

Celestino, Olinda y Meyers, Albert. 1981. Las cofradías en el Perú: región central. Frankfurt: Verlag Klaus Dieter Vervuert.

Cruz, Enrique N. 1997. «De igualdades y desigualdades: Cofradías en el Jujuy colonial». Anuario del IEHS 12: 293-305.

Cruz, Enrique N. 2003. Cofradías, Montepíos y Hospitales en la sociedad Jujeña del siglo XVIII. Sevilla: Tesis Doctoral Universidad de Sevilla.

Cruz, Enrique N. 2007. «Una cofradía urbana de indios a fines de la colonia: San Pedro de Naturales (Jujuy - Río de la Plata)». Revista Andina 44: 227-248.

Diez Hurtado, Alejandro. 1994. Fiestas y cofradías. Asociaciones religiosas e integración en la historia de la comunidad de Sechura (siglos XVII al XX). Piura: CIPCA.

Doucet, Gastón. 1988. «Sobre cautivos de guerra y esclavos indios en el Tucumán. Notas en torno a un fichero documental salteño del siglo XVIII». Revista de Historia del Derecho 16: 59-152.

Garland Ponce, Beatriz. 1994. «Las cofradías en Lima durante la colonia. Una primera aproximación», en Gabriela Ramos (comp.) La venida del reino. Religión, evangelización y cultura en América, Siglos XVI-XX: Cuzco: Centro de Estudios Regionales Andinos «Bartolomé de Las Casas»: 199-228.

González Fassani, Ana M. 2005. «¿Qué entendemos por cofradía colonial?»: una aproximación a un marco teórico para su estudio», en Hilda R. Zapico (coordinadora) De prácticas, comportamiento y formas de representación social en Buenos Aires, siglo XVII y XIX: Bahía Blanca: ediUNS: 225-261.

Lavrin, Asunción. 1998. «Cofradías novohispanas: economías material y espiritual», en M. del P. López-Cano, G. Von Wobeser, y J. Muñoz Correa (coord.) Cofradías, capellanías y obras pías en América Colonial: México: Universidad Nacional Autónoma de México: 49-64.

Le Goff, Jacques. 1981. El nacimiento del purgatorio. Madrid: Taurus.

Luque Alcaide, Elisa. 1995. La cofradía de Aránzazu de México (16811799). Pamplona: Ediciones Eunate.

Martínez de Sánchez, Ana María. 2005. «La resurrección de los muertos. Significado del espacio sepulcral». Hispania Sacra 57: 109-140.

Minois, Georges. 1994. Historia de los Infiernos. Barcelona: Paidós.

Paniagua Pérez, Jesús. 1995. «Cofradías limeñas: San Eloy y la Misericordia (1597-1733)». Anuario de Estudios Americanos LII-1: 13-35. 
Platt, Tristán. 1989. Los guerreros de Cristo. Cofradía, misa solar y guerra regenerativa en una doctrina Macha (siglos XVIII-XX). La Paz: ASUR - plural.

Rumeu de Armas, Antonio. 1981. Historia de la previsión social en España. Cofradías - gremios - hermandades - montepíos. Barcelona: Ediciones El Albir.

Santamaría, Daniel J. 1999. «Mercaderes, tenderos y prestamistas. La mercantilización de la economía jujeña (1690-1730)». Anuario del IEHS 14: 437-469.

Socolow, Susan M. 1991. Los mercaderes del Buenos Aires virreinal: familias y comercio. Buenos Aires: Ediciones de la Flor.

Sola Corbacho, Juan C. 1999. «Los comerciantes mexicanos frente a la muerte (1765-1800)». Revista Complutense de Historia de América 25: 167-194.

Tausiet Carlés, María. 2005. «Gritos del más allá. La defensa del purgatorio en la España de la Contrarreforma». Hispania Sacra 57: 81-108.

Toscano, Jaime. 1906. El primitivo obispado del Tucumán y la iglesia de Salta. Buenos Aires: Imprenta de M. Biedma e hijo.

Valenzuela Márquez, Jaime. 2010. «Devociones de inmigrantes. Indígenas andinos y plurietnicidad urbana en la conformación de cofradías coloniales (Santiago de Chile, siglo XVII)». Historia 43-1: 203-244.

Vergara, Miguel A. 1942. Estudios sobre historia eclesiástica de Jujuy. Tucumán: Universidad Nacional de Tucumán.

Vitar, Beatriz. 1997. Guerra y misiones en la frontera chaqueña del Tucumán (1700-1767). Madrid: Consejo Superior de Investigaciones Científicas.

Von Wobeser, Gisela. 1994. El crédito eclesiástico en la Nueva España. México: Universidad Nacional Autónoma de México.

Zanolli, Carlos y Alonso, Claudia. 2004. «Santa Bárbara, una cofradía de indios en San Antonio de Humahuaca (1713-1785)». Anuario Historia Regional de las Fronteras IX: 87-109.

Zenarruza, Jorge G. C. 1991. Los vascos en América. Investigación sobre asentamientos vascos en el territorio argentino, siglo XVI a XIX, Tomo I. Buenos Aires: Fundación Vasco-Argentina Juan de Garay. 